\title{
Recurrent Anaplastic Pleomorphic Xanthoastrocytoma
}

National Cancer Institute

\section{Source}

National Cancer Institute. Recurrent Anaplastic Pleomorphic Xanthoastrocytoma. NCI

Thesaurus. Code C160904.

The reemergence of anaplastic pleomorphic xanthoastrocytoma after a period of remission. 